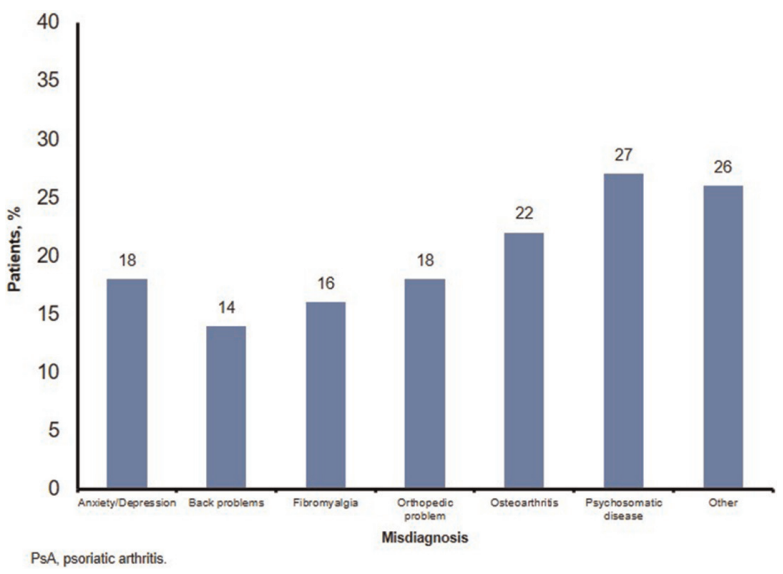

Abstract THU0292 - Figure 1. Misdiagnoses Received Before Diagnosis of PsA ( $N=203$ ). PsA, psoriatic arthritis

Conclusions: This study showed that patients often had substantial delays and misdiagnoses before they received a PsA diagnosis. Increased understanding of the diagnostic barriers may lead to earlier diagnosis and appropriate treatment that may improve outcomes.

REFERENCES:

[1] Haroon M, et al. Ann Rheum Dis 2015;74(6):1045-1050.

[2] Mease P, Armstrong A. Drugs 2014;74(4):423-441.

Acknowledgements: This study was sponsored by Novartis Pharmaceuticals Corporation, East Hanover, NJ.

Disclosure of Interest: A. Ogdie Grant/research support from: Pfizer and Novartis, Consultant for: Abbvie, BMS, Eli Lilly and Company, Novartis, Takeda, and Pfizer, W. B. Nowell Employee of: Global Healthy Living Foundation, E. Applegate: None declared, K. Gavigan Employee of: Global Healthy Living Foundation, S. Venkatachalam Employee of: Global Healthy Living Foundation, M. de la Cruz Employee of: ICON, E. Flood Employee of: ICON, E. Schwartz Employee of: ICON, B. Romero Employee of: ICON, P. Hur Employee of: Novartis Pharmaceuticals Corporation

DOI: 10.1136/annrheumdis-2018-eular.4374

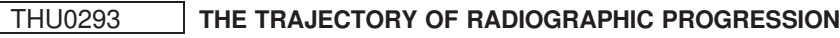 SLOWS AMONGST PATIENTS WITH PSORIATIC ARTHRITIS TREATED WITH ANTI-TNF}

${ }^{1}$ A. Allard, A. Antony ${ }^{1}$, G. Shaddick ${ }^{2}$, D. Jadon ${ }^{3}$, C. Cavill ${ }^{1,4}$, E. Korendowych ${ }^{1}$, N. McHugh ${ }^{1,4}$, W. Tillett ${ }^{1,4}$. ${ }^{1}$ Rheumatology, Royal National Hospital for Rheumatic Diseases, Bath; ${ }^{2}$ Mathematical Sciences, University of Exeter, Exeter,

${ }^{3}$ Rheumatology, Cambridge University Hospitals, Cambridge; ${ }^{4}$ Pharmacy and Pharmacology, University of Bath, Bath, UK

Background: Radiographic damage is an important outcome in psoriatic arthritis (PsA) but the natural history of radiographic progression has not been well described. Randomised Controlled Trials (RCTs) of treatment with anti-TNF have shown reduced damage progression in the short term but long term real world data is lacking.

Objectives: We set out to describe the long term radiographic progression amongst patients with PsA who transitioned from conventional synthetic Disease Modifying Drugs (csDMARDs) to anti-Tumour Necrosis Factor alpha inhibitors (anti-TNF) in routine care.

Methods: A retrospective sample of 28 patients (CASPAR criteria for PsA) was taken from the Bath longitudinal cohort. All patients had radiographs of the hands and feet taken at approximately 3 time points; 5 years before $\left[\mathrm{T}_{0}\right]$, at the time of $\left[\mathrm{T}_{1}\right]$ and 5 years post $\left[\mathrm{T}_{2}\right]$ commencing anti-TNF treatment. 84 radiographs were scored using the Sharp-van der Heijde modified method (VDH) and osteoproliferation was scored using the psoriatic arthritis Ratingen score (PARS) method, by three assessors (AA, AA and WT). The assessors were blinded to the patient details and the order of the $\mathrm{x}$-rays. Inter- and intra-rater reliability was assessed using intra-class correlation coefficients (ICC). Cumulative probability plots were used to describe radiographic progression on csDMARDs ( $T_{0}$ to $T_{1}$ ) compared with subsequent anti-TNF treatment $\left(T_{1}\right.$ to $\left.T_{2}\right)$. Change between probability plots was determined using the two-sample Kolmogorov-Smirnov test (K-S test). This sample size was calculated to ensure $90 \%$ power to determine the smallest detectable difference of the VDH (6.25) to $5 \%$ significance level.
Results: Of the 28 patients 15 were male, the mean age was 61 years (SD 13.4) and mean disease duration at $T_{0}$ was 11.2 years (SD 11.14). The mean study follow up period was 10.2 years (SD 2.76). Inter- and intra-rater reliability was $>0.9$ The median VDH score at baseline was 8.5 (IQR 1.75-27.5). The median scores for erosions, joint space narrowing and proliferation at baseline were 1.5 (IQR 08.5), 4.5 (IQR 1-15) and 7 (SD1-13.5) respectively.

The median change in VDH score on csDMARDs was 11.00 (IQR 3-19.5) and on anti-TNF was 4.00 (IQR 0.75-11.5). The median rate of change in VDH score per year was 2.29 (IQR 0.95-3.81) on csDMARDs and on anti-TNF was 1.04 (IQR 0.16 ) $p=0.012$ (figure 1). These scores correlate with observed improvements in clinical disease outcome measures including tender joint count, swollen joint count and nail score (data not shown).

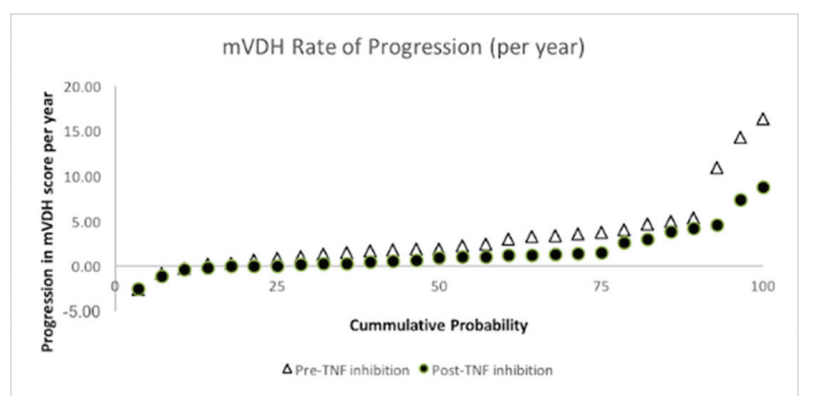

Abstract THU0293 - Figure 1. mVDH rate of progression (per year). $\Delta$ pre-TNF inhibition -post-TNF inhibition

Conclusions: In this real world observational cohort study the rate of radiographic progression slows following commencement of anti-TNF therapy. The overall rate of damage progression was low over long term follow up of more than ten years even amongst this group of more severe patients selected on the basis they progressed to anti-TNF therapy.

Disclosure of Interest: None declared

DOI: 10.1136/annrheumdis-2018-eular.3154

\section{THU0294 5-YEAR EFFICACY AND SAFETY OF APREMILAST TREATMENT IN SUBJECTS WITH PSORIATIC ARTHRITIS: POOLED ANALYSIS OF THE PALACE STUDIES}

${ }^{1}$ A. Kavanaugh, D.D. Gladman ${ }^{2}$, C.J. Edwards ${ }^{3}$, G. Schett ${ }^{4}$, B. Guerette ${ }^{5}$, N. Delev ${ }^{5}$, L. Teng ${ }^{5}$, M. Paris ${ }^{5}$, P.J. Mease ${ }^{6} .{ }^{1}$ University of California, San Diego, School of Medicine, La Jolla, USA; ${ }^{2}$ Krembil Research Institute, Toronto Western Hospital, Toronto, Canada; ${ }^{3}$ University of Southampton, Southampton, UK; ${ }^{4}$ Friedrich-Alexander-Universität Erlangen, Nürnberg und Universitätsklinikum Erlangen, Erlangen, Germany, ${ }^{5}$ Celgene Corporation, Summit, ${ }^{6}$ Swedish Medical Center and University of Washington School of Medicine, Seattle, USA

Background: Apremilast (APR) is an oral phosphodiesterase 4 inhibitor for the treatment of adult patients with active psoriatic arthritis (PsA)

Objectives: The long-term efficacy and safety of APR treatment were evaluated for up to 5 years in subjects with active PsA from the phase 3 PALACE 1, 2, and 3 studies.

Methods: Subjects were randomised at baseline $(B L)(1: 1: 1)$ to receive placebo (PBO), APR $30 \mathrm{mg}$ BID (APR30), or APR $20 \mathrm{mg}$ BID (APR20). PBO subjects were re-randomised (1:1) to APR30 or APR20 at Week 16 (early escape) or Week 24. Double-blind APR treatment continued to Week 52; subjects could continue APR during an open-label, long-term treatment phase for up to 5 years. Safety was assessed at each visit throughout the study.

Results: A total of 1493 subjects were randomised and received $>1$ dose of study medication (PBO: $n=495$; APR30: $n=497$; APR20: $n=501$ ). Of those randomised to APR30 at BL, 66.6\% (331/497) completed 260 weeks of treatment. A Week 52, modified ACR20, ACR50, and ACR70 responses were achieved by $55.3 \%, 26.1 \%$, and $11.9 \%$ of APR30 subjects, respectively, regardless of when APR was started (BL, Week 16, or Week 24). Sustained response rates were observed with continued APR30 treatment at Week 260 (table 1). Marked SJC improvements were seen, with mean percent reduction of $82.3 \%$ at Week 260 ; TJC reduction was $72.7 \%$. At Week $260,62.4 \%$ (136/218) of APR30 subjects with BL enthesitis achieved a MASES of $0 ; 80.9 \%(114 / 141)$ with BL dactylitis achieved a dactylitis count of 0 . A total of $52.6 \%$ of APR30 subjects achieved $\mathrm{HAQ}$-DI MCID $\geq 0.35$ at Week 260 , and low disease activity and remission, as defined by the cDAPSA (score $\leq 13$ ), were achieved by $60.4 \%$ of APR30 subjects. Sustained responses in psoriatic skin involvement were observed with continued treatment at Week 260 in APR30 subjects who had $\geq 3 \%$ BL psoriasis body 
